\title{
Simulation of Shakedown Behavior for flexible Pavement's Unbound Granular Layer
}

\author{
Ainalem Nega ${ }^{1}$, Hamid Nikraz $^{2}, \operatorname{Imad}$ L. Al-Qadi ${ }^{3}$ \\ ${ }^{1} \mathrm{PhD}$ Candidate, Department of Civil Engineering, Curtin University, GPO Box \\ U1987, Perth, WA 6845, Australia; Tel: (+61) 8 9266-2674; Fax: (+61) 8 9266- \\ 2681; Email: Ainalem.Nega@curtin.edu.au \\ ${ }^{2}$ Professor, Head of Department of Civil Engineering, Curtin University, GPO Box \\ U1987, Perth, WA 6845, Australia; Tel: (+61) 8 9266-7573; Fax: (+61) 8 9266-2681; \\ Email: H.Nikraz@curtin.edu.au \\ ${ }^{3}$ Founder Professor of Engineering and Director of Illinois Center for Transportation, \\ University of Illinois, 205 North Mathew Avenue, Urbana, IL 61081, USA; Tel: (+1) \\ 217 265-0427: Fax: (+1) 217 333-1924; Email: alqadi@illinois.edu
}

\begin{abstract}
Full-depth asphalt concrete pavements are generally designed to control fatigue cracking and reduce potential rutting when subjected to repeated heavy traffic loads. A particular interesting question is whether a limit load exists below which excitation shakedown in the sense that the granular layer does not accumulate further deformation. Although pavement design guides give more weight to asphalt concrete layer failures, granular failure may not be ignored; especially for thin layers and/or heavy load. The behavior of granular layers used in base and, sub-base layers of flexible pavement is complicated due to its nonlinear elastoplastic response when subjected to dynamic traffic loading. The objective of this paper is to present a new simplified simulation model for the Shakedown behavior of granular layer in flexible pavement. This method is integrated with Mohr-Coulomb criterion, which is used and applied to simulate the response of unbound granular layers to dynamic loading in a numerical analysis. The results of analysis are then compared to simplify the results of modeling without considering shakedown effects and then, the conclusions are drawn.
\end{abstract}

Keywords: Dynamic analysis; Flexible pavement; Mohr Coulomb criterion; Numerical simulation; Shakedown; Unbound granular Layer (UGL)

\section{Introduction}

A structural formation of the elastic-plastic problem and/or shakedown theory has been adopted to account for this complex response in the form given by Martin et al. (1987). This framework is essentially identical to that used by (Cohn, Maier \& Grierson 1979). The formation was presented in discrete terms, in a manner which can readily be identified with finite element approximations (Martin et al. 1987).

The realistic analysis of pavement performance requires an approach that recognized the incremental mode of failure of such structure when subjected to repeated moving loads (Ghadimi, Nega \& Nikraz 2015), and that theory of structural shakedown provides such an approach (Sharp 1985). The shakedown concept has been used to describe the behaviour of conventional engineering structure under repeated cyclic loading (Werkmeister, Dawson \& Wellner 2001). The interesting 
question is whether a critical stress level exists between stable and unstable condition in pavement structure. The concept maintains four categories of material response are under repeated loading: purely elastic, elastic shakedown, plastic shakedown, and incremental collapse (Werkmeister, Dawson \& Wellner 2001). The shakedown concept is used to indicate the behavior of UGM based on the data by AASHO experiment (AASHTO1986), while the method of limit analysis was to indicate the lower and upper bound limits of UGM in shakedown condition.

Chazallon, Hornych and Mouhoubi (2006) developed a new elastoplastic model for the long-time behaviour of unbound granular material in flexible pavement taken into account in both isotopic and kinematic harding. In this model, modified Boyce model (Boyce 1980) was implemented in order to account for sand response. And then, Allou, Chazallon and Hornych (2007) implemented the constrictive mathematical material models that was presented by Habiballah and Chazallon (2005) into a finite elements modeling (FEM) simulation of a low volume traffic road.

Based on repeated load triaxial tests, a further general procedure has been developed by Chazallon et al. (2009) for the determination of the material parameters of constitutive model in order to integrate the previous studies (Allou, Chazallon \& Hornych 2007) in a FEM modelling by taking into account the Boyce model (Boyce 1980) and shakedown for UGM layers. Another, 2D-FE simulation is conducted by Ling and Lin (2003) where the response of reinforced asphalt pavement concrete under plane strain model condition subjected to monotonic loading is investigated. The simulation is run through PLAXIS program and UGM elastoplastic behaviour is considered through Mohr-Coulomb Criterion (Ghadimi, Nega \& Nikraz 2015) in order to obey the associated and non-associated flow rules.

Saad, Mitri and Poorooshasb (2006) investigated the numerical simulation to evaluate the benefits of integrating a high modulus into the pavement foundation and/or design criteria. The fatigue resistance of the pavement system is evaluated through the maximum tensile strain transmitted to the bottom of the asphalt concrete layer whereas the maximum compressive strain transmitted to the top of subgrade to evaluate the rutting resistance of the pavement. Material elastoplastic behavior is considered through Drucker-Plager model and simulation is run by ADINA.

Ghadimi, Nega and Nikraz (2015) integrated a simulation of shakedown behavior in pavement granular layer in new constitutive model based on Mohr-Coulomb Criterion in FEM simulation in ABAQUS that was initially the experimental for UGM shakedown presented by Chazallon et al. (2009). In sufficient evidence is currently available to confirm the reliability of the proposed linkage between shakedown ranges defined via repeated load triaxial (RLT) test and in-situ performance of UGM.

The main objective of this paper is to present a new simplified simulation model for the Shakedown behavior of unbound granular layer (UGL) in flexible pavement. This method is integrated with Mohr-Coulomb criterion, which is used and applied to simulate the response of unbound granular layers to dynamic loading in a numerical analysis.

\section{Description of Constitutive Models}

The formulation and solution of incremental problem in elastic-plastic solid is a fundamental problem in plasticity. Powerful techniques are available in finite element 
methods for the solution of this class of problem, and solutions can be carried out fairly routinely in standard finite element codes.

The analyses presented here tries to take into account the elastic materials where the applied repeated stress is sufficient small such that no element of the material enters the yield condition because the loading and unloading path in stress-strain excursion is the same. In other words, there is no any residual strain produced in loading cycles. From the first stress-strain excursion, all deformations are fully recovered. However, in case of elastoplastic, there would be some residual strain in each loading cycles if the amplitude of loading exceeds the yield criterion.

The solution for such kind of material is through introducing constitutive models. The oldest and still the most useful widely applied constitutive models to model UGM response of flexible pavement layers (FPL) are Mohr-Coulomb criterion and Drucker-Prager (Werkmeister, Dawson \& Wellner 2001).

The yield criterion proposed by Coulomb (1773) is in term of shear stress $\tau$ and normal stress $\sigma_{n}$ acting on a plane (Yu 2006). It suggests that the yield begin as long as the shear stress and the normal stress satisfy the following equation:

$$
|\tau|=c+\sigma_{n} \tan \phi
$$

where $c$ and $\phi$ are the cohesion and angle of internal friction for soil. Mohr-Coulomb yield, which is equation (2) and Drucker-Prager's, (equation 3), yield surface on a deviatoric plane is shown in Figure 1.

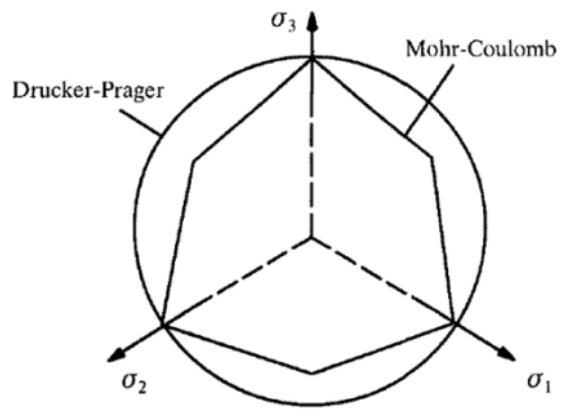

Figure 1. Mohr-Coulomb and Drucker-Prager's yield surface on a deviatoric plane

In term of the principle stress, Coulomb's yield criterion equation can be expressed as:

$$
f=\sigma_{1}-\sigma_{3}\left(\sigma_{1}+\sigma_{3}\right) \sin \phi-2 c \cos \phi=0 \text { for } \sigma_{1} \geq \sigma_{2} \geq \sigma_{3}
$$

where $\sigma_{1}, \sigma_{2}$ and $\sigma_{3}$ are three principle stress; and $c$ and $\phi$ and are cohesion and angle of internal friction, respectively. To overcome the limitation of the von Mises yield function (von Mises yield is not suitable for modelling), Drucker and Prager (1952) proposed the following revised function for frictional soils

$$
f=\sqrt{J_{2}}-a I_{1}-k=0 \ldots . \text { where } a=\frac{2 \sin \phi}{\sqrt{3}(3-\sin \phi)} \text { and } k=\frac{6 c \cos \phi}{\sqrt{3}(3-\sin \phi)}
$$

where $I_{1}$ and $J_{2}$ are first invariant principle stress and second invariant of deviator stress tensor, respectively, and a and $\mathrm{k}$ are material constants for use in analysis. The above equation (3) yield a one-to-one relationship between stress and strain can be expresses in the rate forms of this stress-strain relationship as equation given below: 


$$
\dot{\sigma}_{i j}=\frac{\partial^{2} U_{S}}{\partial \varepsilon_{i j} \partial \varepsilon_{k l}} \dot{\varepsilon}_{k l}=D_{i j k l} \dot{\varepsilon}_{k l} \text { and } \dot{\varepsilon}_{i j}=\frac{\partial^{2} U_{S}}{\partial \sigma_{i j} \partial \sigma_{k l}} \dot{\sigma}_{k l}=C_{i j k l} \dot{\sigma}_{k l}
$$

In the above equation (4), the thermodynamic laws are always satisfied because energy cannot generate through load cycles, and materials are identical for loading and unloading. If the $\dot{\sigma}_{i j}=\dot{\varepsilon}_{i j}$, which are mentioned on above equation (4) and then, equation can be written as:

$$
\sigma_{i j}^{n}=C_{i j k l}^{n} \varepsilon_{k l}^{n}
$$

One of the first interpretations that can be applied in shakedown concept is to describe the variation of permanent triaxial deformation or limit the state of plastic strain, $\varepsilon^{p}$, with the number of cyclic loading, $\mathrm{N}$. The relationship of these can mathematically described with an equation as:

$$
\varepsilon_{i}^{p}=f_{i}(N)
$$

The above equation (6) can be differentiating in term of loading time, t, and be expressed as:

$$
\frac{\partial \varepsilon^{p}}{\partial t}=\frac{\partial f_{i}(N)}{\partial N} \varepsilon_{0}^{p}
$$

where $\varepsilon^{p}$ and $N$ are plastic strain and number of cyclic loading, respectively. $f$ is the yield function that determines the direction of plastic strain. Under plastic strain field, the minimal and maximal cyclic loading is a monotonic periodic scalar function, which varies between 0 and 1 . The expression can be written as following:

$$
\left\{\begin{array}{l}
N=1 \Rightarrow \frac{\partial f_{i}(1)}{\partial N}=1 \\
N=\infty \Rightarrow \frac{\partial f_{i}(1)}{\partial N}=0
\end{array}\right.
$$

By using an elastic strain-strain relation, we can determine the elastic strain rate from equation (7) and (8) as

$$
\partial \varepsilon_{i j}^{e}=C_{i j k l} \partial \sigma_{k l} \Rightarrow C_{i j k l}=\frac{\partial \varepsilon_{i j}^{e}}{\partial \sigma_{i j}}
$$

where $C_{i j k l}$ and $\partial \varepsilon_{i j}^{e}$ are elastic compliance matrix and elastic strain rate, respectively. From the shakedown concept, Finally, using equation (7), (8) and (9), the shakedown constitutive model either for elastic or plastic shakedown has the ability of modification for both cyclic loading and stress state (normal and shear stress) in relation to the asphalt surface layers.

Equation (11) designates the newly developed constitutive model for the shakedown UGM of flexible pavement:

$$
\begin{aligned}
& \left(C_{i j k l}^{n_{i}}\right)^{\dot{\hat{S}}}=\left(\frac{1}{c} \cdot \frac{\partial f_{i}(N)}{\partial N}\right)\left(C_{i j k l}^{n_{i}}\right)^{e p}+\left(1-\frac{1}{c} \cdot \frac{\partial f_{i}(N)}{\partial N}\right)\left(C_{i j k l}^{n_{i}}\right)^{\hat{e}}+\left(1-\frac{1}{c} \cdot \frac{\partial f_{i}(N)}{\partial N}\right)\left(C_{i j k l}^{n_{i}}\right)^{e} \\
& \left(C_{i j k l}^{n_{i}}\right)^{\hat{S}}=\left(\frac{1}{c} \cdot \frac{\partial f_{i}(N)}{\partial N}\right)\left(C_{i j k l}^{n_{i}}\right)^{e p}+\left(1-\frac{1}{c} \cdot \frac{\partial f_{i}(N)}{\partial N}\right)\left(C_{i j k l}^{n_{i}}\right)^{\hat{e}}+\left(1-\frac{1}{c} \cdot \frac{\partial f_{i}(N)}{\partial N}\right)\left(C_{i j k l}^{n_{i}}\right)^{e}
\end{aligned}
$$

where $C^{\hat{S}}$ and $C^{e p}$ are denote the shakedown and elastoplastic constitutive models of the unbound granular materials, respectively. $C^{\hat{e}}$ and $C^{e}$ are the inelastic and purely 
elastic constitutive models, in the order given. The superscript $\mathrm{n}$ and $\mathrm{N}$ are the rate and the number of cyclic loading. The letter $c$ is a material constant that refer to the hardening of the UGM, and if there no residuals in the process and then, $c$ can be denotes as, $(c=1)$ and be used as multipliers. The shakedown constitutive model, $\widehat{\boldsymbol{S}}$ , is gradually slowdown from elastoplastic constitutive model, $\boldsymbol{C}^{\boldsymbol{e p}}$, to purely elastic constitutive model, $\boldsymbol{C}^{\boldsymbol{e}}$. There is an inelastic, $\boldsymbol{C}^{\hat{\boldsymbol{e}}}$, stage in between the changing process before it reaches purely elastic (i.e. $100 \%$ elastic).

\section{D - FE Modelling of Flexible Pavement Layers}

This constitutive model is examined against the laboratory data that was done by Habiballah and Chazallon (2005). In addition, constitutive model is also compared to Chazallon et al. (2009) and Ghadimi, Nega and Nikraz (2015) constitutive models. This step is conducted and authors allowed using their laboratory results to verify the performance of this constitutive model. In this 2D-FE numerical simulation, a repeated load triaxial cell is used and simulated with axisymmetric model using ABAQUS. And then, A stages of stress state configuration for flexible pavements is set according to (Habiballah \& Chazallon 2005) and simulated on the model.

Numerical simulation of developed plastic strain with number of load repetitions against the laboratory test that was published by Habiballah and Chazallon (2005) is shown in Figure 2. The material properties of unbound granular material that was used for verification are demonstrated in Table 1. The simulation has a triaxial cylindrical $20 \mathrm{~cm}$ height and $10 \mathrm{~cm}$ diameter sample and is modeled with low number of 100 cycle's linear quadrilateral element of CAX4R. The different stress ratio $q / p$ is defined by the ratio of deviatoric stress $\left(q=\sigma_{1}-\sigma_{3}\right)$ to normal stress or confining pressure, $\left(p=\left(\sigma_{1}+2 \sigma_{3}\right) / 3\right)$ (Chazallon, Hornych \& Mouhoubi 2006; Habiballah \& Chazallon 2005).

\section{Table 1: Material Properties of UGM Used for Verification}

\begin{tabular}{|l|c|c|c|}
\hline UGM properties & \multicolumn{2}{|c|}{ Elastic moduli $(E), \mathrm{MPa}$} & Poisson's ratio $(v)$ \\
\hline Elastic & \multicolumn{2}{|c|}{$E=200$} & $v=0.3$ \\
\hline Plastic & $\phi=44^{\circ}$ & $\mathrm{c}=12.26 \mathrm{kPa}$ & $\Psi$ dilation $=39^{0}$ \\
\hline
\end{tabular}



Figure 2. Simulation of developed plastic strain against the laboratory test (Verification) 
Numerical simulation of three layered flexible pavement: Asphalt, Base (UGM) and Subgrade layers are modeled in ABAQUS and MATLAB. The simulation is modeled with $740 \mathrm{kPa}$ UDP (uniformly distributed pressure) on radius of $9.0 \mathrm{~cm}$ over the circular area. The pressure and loading area are selected and were modeled with total medium of $10 \mathrm{~m} \mathrm{x} 20 \mathrm{~m}$ according the Australian Standard for design loads on structure (Austroads 2012). Figure 3 shows the FEM model of the three layered flexible pavement. As it can be seen from the developed model, the loading tire is not affected by the boundary condition. This showed that the design load on the structure has a capacity to resist deformation because it was design in the way that boundary condition of flexible pavement layers should not affected by repletion of cyclic traffic loading.

The dimension of this model is 100- $\mathrm{R} \times 200-\mathrm{R}$ (loading radius) both in horizontal and vertical direction, repectively. These dimensions are within the ranges of the previous research studies that were recommended. For example, Kim, Tutumluer and Kwon (2009) modeled an ABAQUS numerical simulation for axisymmetric model with a medium of $140-\mathrm{R}$ in vertical and $20-\mathrm{R}$ in horizontal. They suggested that effect of boundary condition would be neglected if it has to be modeled with this medium. Similarly, Ghadimi, Nega and Nikraz (2015) modeled with a medium of 111-R and $222-\mathrm{R}$ in horizontal and vertical direction, in the given order, in ABAQUS simulation, and they are satisfied with the outcome of the results. However, Huang (1993) suggested the boundaries need to be at 50- times R in vertical and 12 time $\mathrm{R}$ in horizontal direction of the layered flexible pavement for modeling.

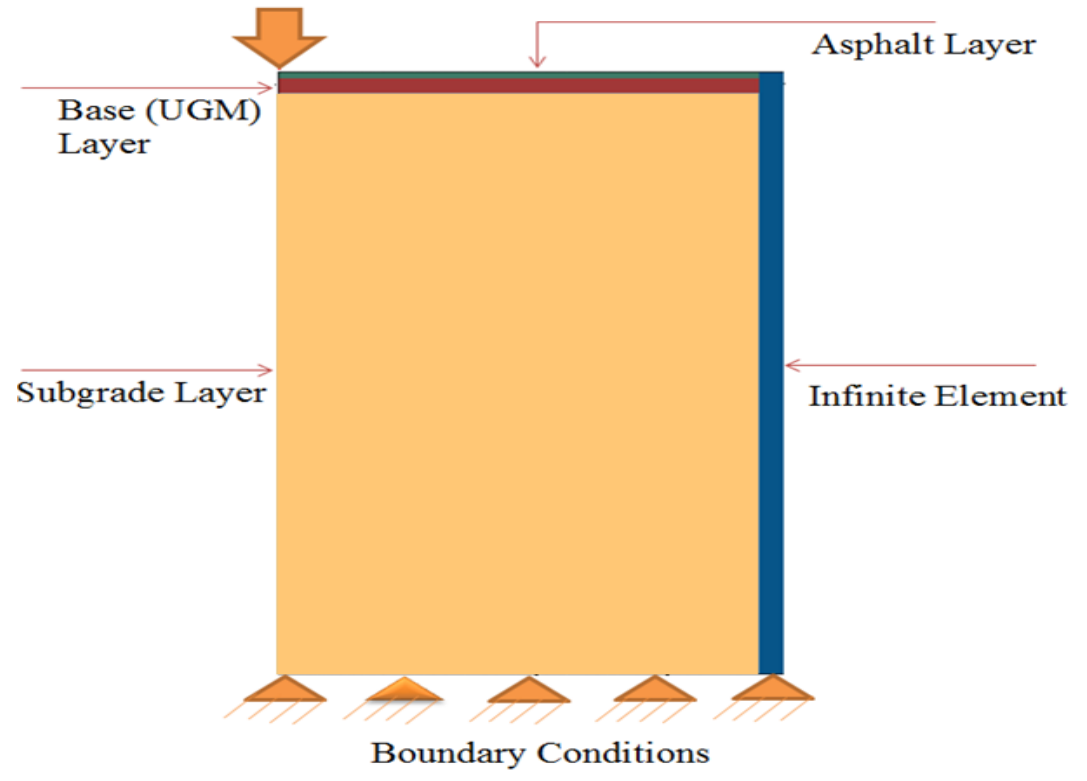

Figure 3. FEM Model of Three Layered Flexible Pavement

The asphalt pavement concrete is modeled with a linear elastic material thickness of $20 \mathrm{~cm}$. The subgrade layer is modeled according to (Drucker \& Prager 1952). An axisymmetric infinite element does not represent the true solution behavior as being infinite in the far field. Due to the linear behavior in the field, the infinite element does a harmonic behavior with the finite element in a layered half-space under surface pressure. 
For the base layer (UGM), two constitutive models: Mohr-Coulomb criterion and Shakedown theory are carried out for a thickness of $50 \mathrm{~cm}$. In the first numerical simulation, the constitutive models is modeled according to Mohr-Coulombs criterion (Coulomb 1773) and then, In the second simulation according the application of shakedown theory to pavement design stated by (Collins \& Boulbibane 2000) so that the effect of shakedown in flexible pavement will be fully understand. The models consists 15000 element in total, which is also includes CAX4R and CINAX4 elements for the layered medium and infinite space, respectively. An efficient returning mapping algorithms that was introduced by Clausen, Damkilde and Anderson (2007) was inserted as unbound granular materials constitutive model, and was also coded in UMAT under ABAQUS simulation. The material properties used for simulation of the layered flexible pavement is shown in Table 2.

Table 2: Material Properties for Flexible Pavement Model

\begin{tabular}{|l|c|c|c|c|c|c|}
\hline $\begin{array}{l}\text { Pavement } \\
\text { Layer }\end{array}$ & $\begin{array}{c}\text { Moduli, } \\
\text { E, MPa }\end{array}$ & $\begin{array}{c}\text { Poisson's } \\
\text { Ratio }(\mathrm{v})\end{array}$ & $\begin{array}{c}\text { Density } \\
\left(\mathrm{kg} / \mathrm{m}^{3}\right)\end{array}$ & $\begin{array}{c}\text { Internal } \\
\text { Friction, } \phi\end{array}$ & $\begin{array}{c}\text { Angle of } \\
\text { Dilation, } \Psi\end{array}$ & $\begin{array}{c}\text { Cohesion } \\
\mathrm{c}(\mathrm{kPa})\end{array}$ \\
\hline Asphalt $20 \mathrm{~cm}$ & 2800 & 0.40 & 2200 & 0 & 0 & 0 \\
\hline Base $50 \mathrm{~cm}$ & 500 & 0.30 & 1800 & 35 & 17 & 7 \\
\hline Subgrade & 50 & 0.35 & 1700 & 20 & 15 & 7 \\
\hline
\end{tabular}

The dynamic finite element simulation has modeled by implicit in ABAQUS to reveal the formulation processes of primarily. The loading is presumed to be a haversine periodical pressure in $7 \mathrm{~s}$. It has a $0.1 \mathrm{~s}$ loading time and followed by rest period of $0.9 \mathrm{~s}$. The loading cycles are shown in Figure 4 . From the modeled data presented, it can be seen that the pressure load of tire is gradually increased to reach a maximum peak and then, decreased to zero. This showed that the strain continues to develop due to unloading stress distribution and then, followed by 0.9 s rest period. Roman, Roger and Walla (1989) evaluated the effect of tire pressure on flexible pavement response and performance. The data showed little effect due to tire pressure at all load levels. On the other hand, on the basis of classical fatigue models, the increased cracking was found to result primarily from the combined effects of higher pavement temperature and thinner pavement structure.

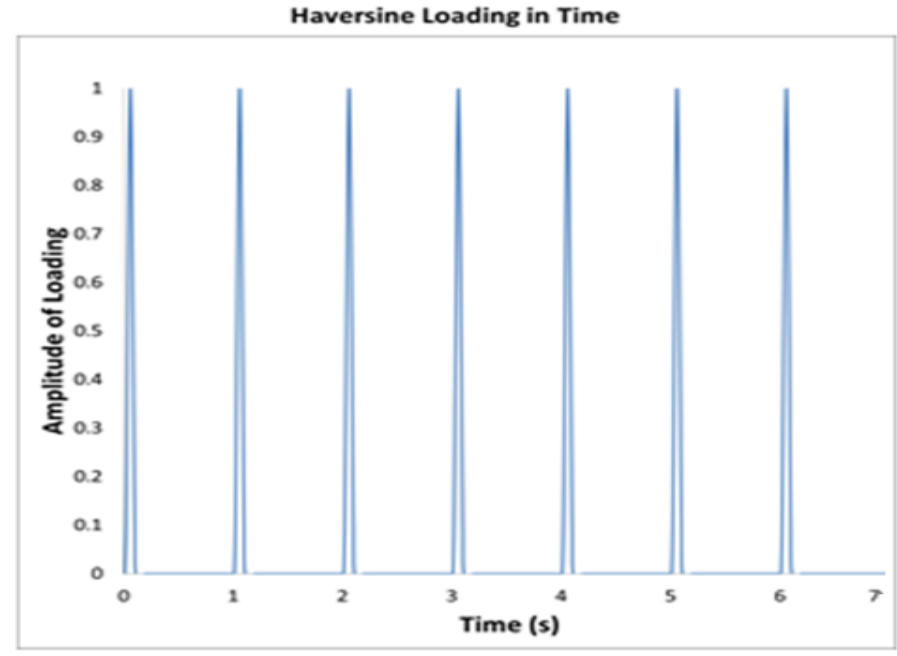

Figure 4. Haversine periodic loading versus time 


\section{Shakedown Analysis for Flexible Pavement UGM Layers}

The shakedown concept has been used to describe the behavior of conventional engineering under cyclic loading. The resulting permanent deformation, which accumulated with the repeated load, was described and compared with types of response usually described by the shakedown approach. The method of description could provide a power material assessment and pavement design tool for engineering UGM pavement bases.

The total vertical strain that was developed in this model for both Mohr-Coulomb criterion and Shakedown constitutive model is shown in Figure 5 and 6, respectively. As it can be seen from analysis, the contours' range of the shakedown model has less strain (i.e. $-9.04 \times 10^{-5}$ to $3.67 \times 10^{-5}$ ) as compared to Mohr-Coulomb criterion model (i.e. $-1.21 \times 10^{-5}$ to $1.34 \times 10^{-5}$ ). It is should be notice from the analysis that the vertical strain is design of flexible pavement is one of the critical which the rutting of the pavement is controlled. Therefore, understanding of the shakedown concept and also give a sound consideration for its effect during pavement design might reduce the risk level of permanent deformation in the UGL in pavement construction. If shakedown concept has ignored, it might lead to pavement overdesign and then, rutting will control the criterion.

Collins and Boulbibane (2000) analyzed the mechanical response of an unbound pavement to the repeated loading of traffic, and pavement is modeled as a layered elastic/plastic structure by the concept of shakedown theory. Results demonstrated that the concept of shakedown theory can lead to design procedures in which the base course thickness can be deduced as a function of the applied and the strength and stiffiness properties of subgrade and base course. They finally summarized that despite the shortcoming, it is argued that the concept and technique of shakedown theory has much to offer to the pavement engineers. Similarly, Habiballah and Chazallon (2005) summarized the rutting of flexible pavement which occurs in the UGLs put in evidence the lack of precision in the design method. They described the shakedown theory method can be an alternative to the step-by-step method for the UGM behavior modelling under large cycle is complex.
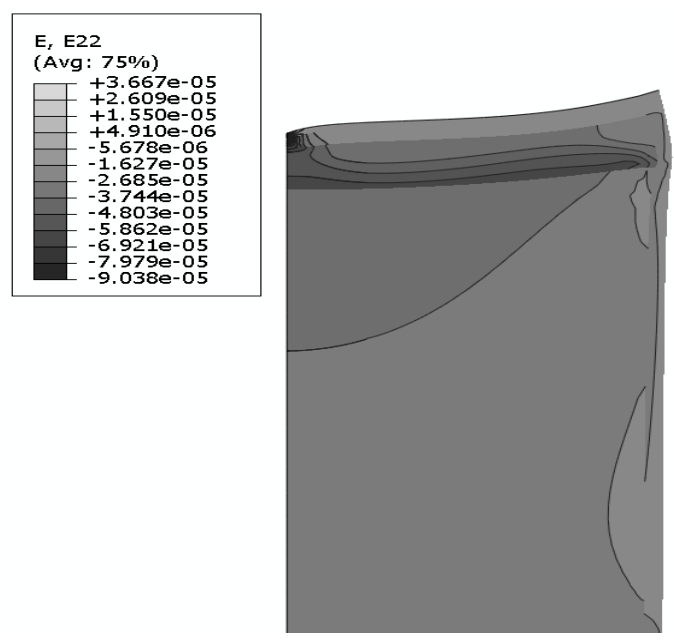

Figure 5. Vertical strain in Shakedown Model
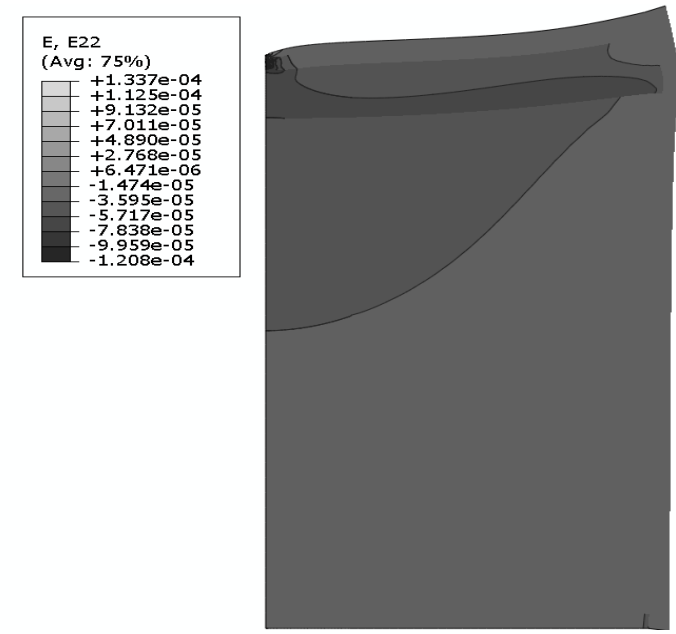

Figure 6. Vertical strain in Mohr-Coulomb Model 
From Figure 1, mathematically the direction of equivalent plastic strain flow rate for Mohr-Coulomb criterion plasticity can be expressed by the following equation:

$$
\mathrm{d} \varepsilon^{p l}=\frac{\mathrm{d} \varepsilon^{-p l}}{g} \frac{\partial G}{\partial \sigma} \ldots . \text { where } g \text { can be written as: } g=\frac{1}{c} \sigma: \frac{\partial G}{\partial \sigma}
$$

By substitution $g$ into equation (11) and also integrating and then, the equation (11) can be simplify as:

$$
\varepsilon^{-p l}=\int \frac{1}{c} \sigma: \mathrm{d} \varepsilon^{p l}
$$

where $\mathrm{c}$ is the constant material cohesion; $\sigma$ is stress tensor and $\mathrm{d} \varepsilon^{p l}$ is plastic strain increment tensor. It is understandable that the magnitude of equivalent plastic strain is determine by the above equation in each element. The distributions of equivalent plastic strain for Mohr-Coulomb and Shakedown model are shown in Figure 7 and 8. As it can be seen from model, shakedown model has a high equivalent plastic strain (i.e. $\left.4.08 \times 10^{-4}\right)$ as compared to equivalent plastic strain $\left(7.95 \times 10^{-4}\right)$ in Mohr-Coulomb materials. This indicates that the effects of shakedown behavior are more than the material in Mohr-Coulomb even if a reasonable difference of equivalent plastic strain distributions is acceptable for both models. Of particular important in this case is whether a given a pavement structure will experience accumulation of plastic strain or increase in plastic strain will cease to occur, there by loading to stable or shakedown.

Boulbibane et al. (2005) reviewed a new mechanistic approach to unbound pavement design based on the shakedown theory. Results show minimum shakedown load are found by varying the geometry of the proposed failure mechanisms. Similarly, Chazallon et al. (2009) presented a finite element program for the modelling of rutting of two flexible pavement with shakedown theory and FEM. The program incorporates a permanent deformation model for unbound granular material based on the concept of the shakedown theory. Comparisons of model predication with result of cyclic triaxial test were fairly good result have been obtained.
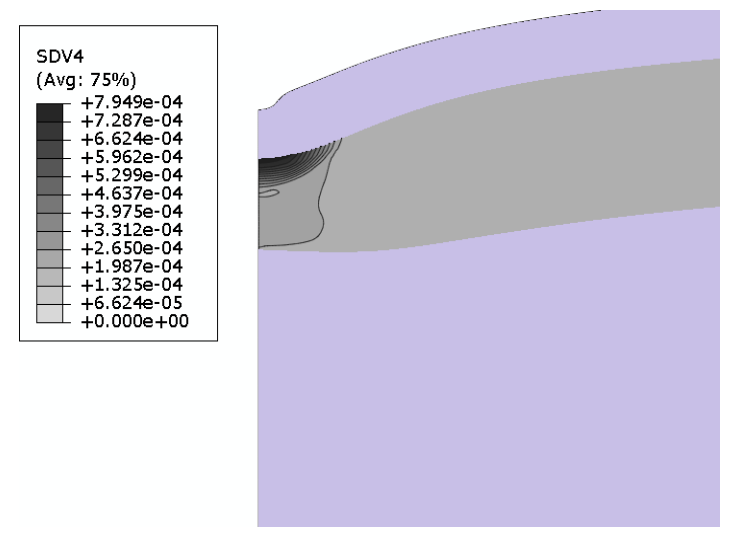

Figure 7. Equivalent plastic strain in Mohr-Coulomb Model

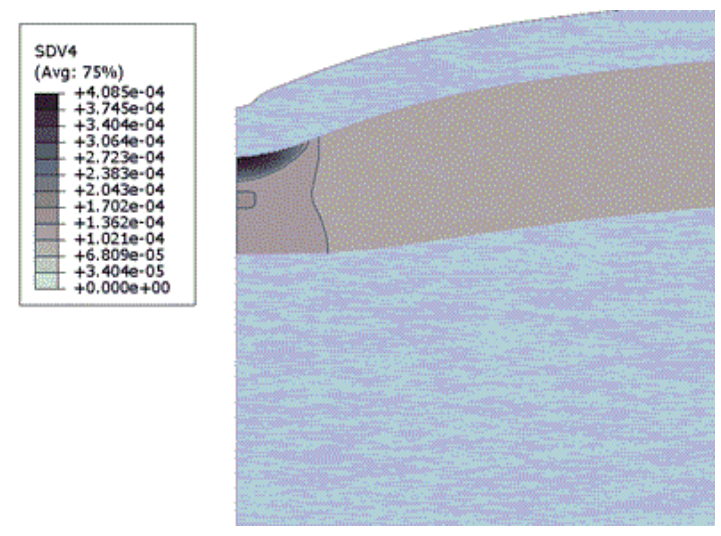

Figure 8. Equivalent plastic strain in Shakedown Model

To investigate the particular effect of shakedown behavior more adequately, another second element was selected from the beneath of asphalt concrete layer at the center of loading, and this element had high vertical stress during loading cycles. Figure 9 shows the development of equivalent plastic strain during loading time for 
both Mohr-Coulomb and Shakedown at the center of this element. As it can be seen from the figure, the equivalent plastic strain in shakedown model is less developed as compared to the Mohr-Coulomb model within 7s time period of dynamic analysis. If it was simulated for a longer loading time, the effect of shakedown could behave differently. The maximum peak of accumulated plastic strain in Mohr-Coulomb has reached $2.70 \times 10^{-4}$ while $2.50 \times 10-^{4}$ in shakedown models.

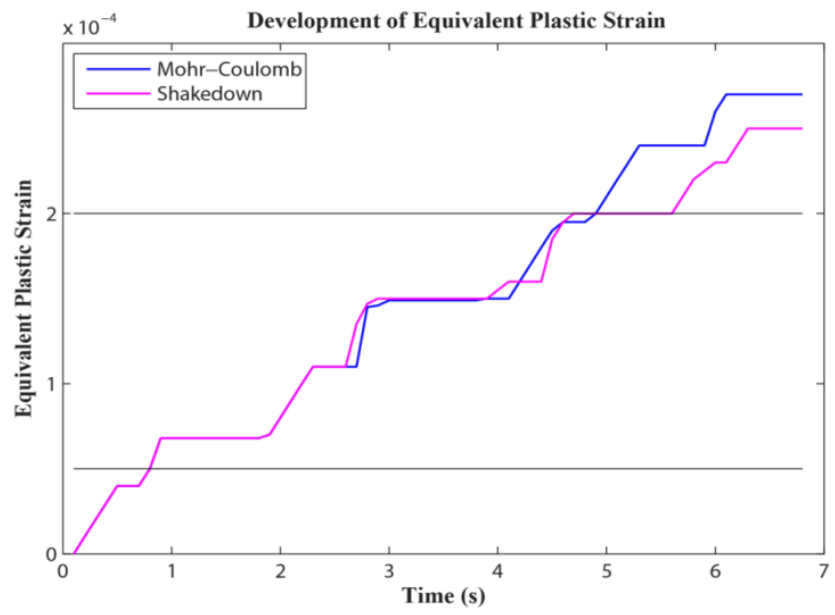

Figure 9. Equivalent plastic strain versus time of Mohr-Coulomb and Shakedown

Stress -stain curve are an extremely important of a material mechanical properties in modern engineering materials. They are important graphical measure of hysteresis loop if the loads are high enough to induce characteristic of plastic shakedown behavior, while engineering stress-strain curve are used within elastic limit. As the result of these, the plastic shakedown behavior can easily understood if and if the hysteresis loop of stress-strain curve are taken into consideration. The stress-stain hysteresis's loop for shakedown model (i.e. for second element below the asphalt concrete layer) is shown in Figure 10. As it can be seen from the hysteresis loop, the behavior of the material is declining towards to the elastic behavior. This shows the material shakedown response is different from the material in Mohr-Coulomb plastic criterion. It can also be understood that the materials behavior in this model is stiffer because of increasing in loading cycles.

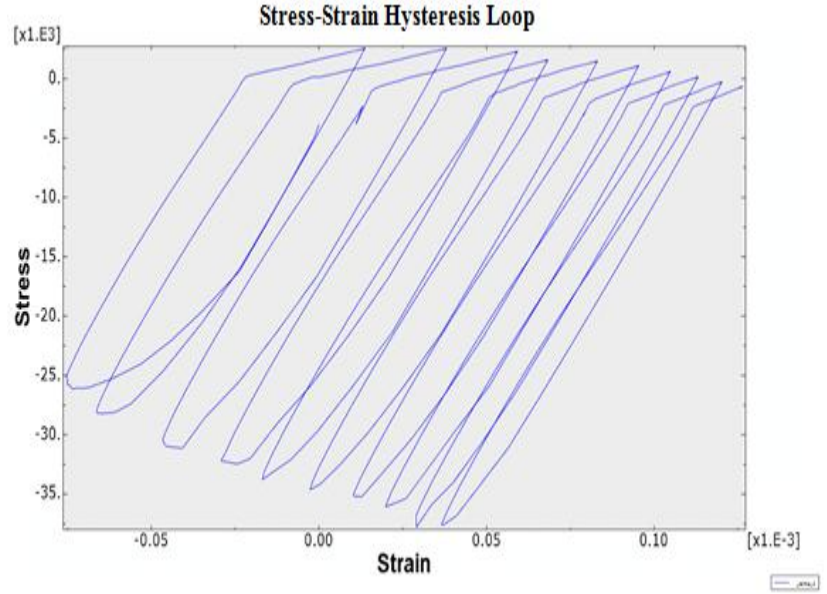

Figure 10. Stress-strain hysteresis loop during Shakedown 


\section{Conclusions}

This paper presents a numerical simulation model for shakedown behavior for flexible pavement's unbound granular layer (UGL). This method is integrated with Mohr-Coulombs criterion, which is used and applied to simulate the response of unbound granular material (UGM) to dynamic loading in a numerical analysis. A new constitutive model is developed based on Mohr-Coulomb criterion and DruckerPlager method for flexible pavement unbound granular materials (UGM).

The new developed constitutive model is capable of considering shakedown effect in base UGL and predicting the various types of observed flexible pavement failure and the effect of various design parameters. The implementation of this new developed constitutive model is verified against published results of laboratory test data measured shakedown for UGM. This model also compared with other's a simplified model studies of pavement unbound granular layers based on the shakedown theory and Mohr-Coulomb criterion for verification.

This constitutive model is numerically implemented in dynamic FE simulation in ABAQUS and results are compared to Mohr-Coulomb criterion. Results has shown $50 \%$ reduction of vertical plastic stain of the base (UGL) layer with shakedown model as compared to Mohr-Coulomb after 7s repetion of cyclic loading. This justified that it is necessary to give a sound consideration to shakedown effect in structure of flexible pavement layers and various design parameters because this justification can provide a powerful material assessment and pavement design tool for engineering UGM pavement bases. If shakedown effect has neglected in shakedown concept and pavement design, the risk level of pavement deformation in the UGL in pavement construction might critically increase.

\section{Acknowledgment}

The research described in this paper is made possible through the award of Australia Postgraduate Award (APA) by the Australia Government and Curtin Reseach Scholarship Award (CRS). The financial support by Australia Government and Curtin University is gratefully acknowledged, as is the value of supervision and advice given by Professor Hamid Nikraz and Professor Imad L. Al-Qadi is also much appreciated.

\section{References}

Allou, F, Chazallon, C \& Hornych, P 2007, 'A numerical model for flexible pavements rut depth evolution with time', International Journal for Numerical and Analytical Methods in Geomechanics, vol. 31, no. 1, pp. 1-22.

American Association of State Highway and Transportation Officials 1986, AASHTO Guide for design of pavement structures, American Association of State Highway and Transportation Officials, Washington, DC, USA.

Austroads 2012, Guide to pavement technology Part 2: pavement structural design, AGPT02-12, Austroads, Sydney, Australia.

Boulbibane, M, Collins, IF, Ponter, ARS \& Weichert, D 2005, 'Shakedown of Unbound Pavements', Road Materials and Pavement Design, vol. 6, no. 1, pp. 81-96.

Boyce, JR 1980, ' A non-linear model for the elastic behaviour of granular materials under repeated loading', in Proc., Int. Symp. of Soils under Cyclic and Translent Loading, Balkema, Rotterdam, The Netherlands, pp. 285-294. 
Chazallon, C, Allou, F, Hornych, P \& Mouhoubi, S 2009, 'Finite elements modelling of the long-term behaviour of a full-scale flexible pavement with the shakedown theory', International Journal for Numerical and Analytical Methods in Geomechanics, vol. 33, no. 1, pp. 45-70.

Chazallon, C, Hornych, P \& Mouhoubi, S 2006, 'Elastoplastic Model for the Long-Term Behavior Modeling of Unbound Granular Materials in Flexible Pavements', International Journal of Geomechanics, vol. 6, no. 4, pp. 279-289.

Clausen, J, Damkilde, L \& Andersen, L 2007, 'An efficient return algorithm for nonassociated plasticity with linear yield criteria in principal stress space', Computers \& Structures, vol. 85, no. 23-24, pp. 1795-1807.

Cohn, MZ, Maier, G \& Grierson, DE (eds) 1979, Engineering plasticity by mathematical programming, Pergamon Press, New York.

Collins, IF \& Boulbibane, M 2000, 'Geomechanical Analysis of Unbound Pavements Based on Shakedown Theory', Journal of Geotechnical and Geoenvironmental Engineering, vol. 126, no. 1, pp. 50-59.

Coulomb, CA 1773, 'Essai sur une application des règles de maximis et minimis à quelques problèmes de statique, relatifs à l'architecture', Mem. pres. par div. savants, vol. 7, pp. 343-382.

Drucker, DC \& Prager, W 1952, 'Soil mechanics and plasticity analysis for limit design', Quarterly of Applied Mathematics, vol. 10, pp. 156-165.

Ghadimi, B, Nega, A \& Nikraz, H 2015, 'Simulation of shakedown behavior in pavement's granular layer', International Journal of Engineering and Technology, vol. 7, no. 3, pp. 198-203.

Habiballah, T \& Chazallon, C 2005, 'An elastoplastic model based on the shakedown concept for flexible pavements unbound granular materials', International Journal for Numerical and Analytical Methods in Geomechanics, vol. 29, no. 6, pp. 577-596.

Huang, YH 1993, Pavement analysis and design, 2nd edn, Prentice Hall Inc., New Jersey, USA.

Kim, M, Tutumluer, E \& Kwon, J 2009, 'Nonlinear pavement foundation modeling for threedimensional finite-element analysis of flexible pavements', International Journal of Geomechanics, vol. 9, no. 5, pp. 195-208.

Ling, H \& Liu, H 2003, 'Finite Element Studies of Asphalt Concrete Pavement Reinforced with Geogrid', Journal of Engineering Mechanics, vol. 129, no. 7, pp. 801-811.

Martin, JB, Reddy, BD, Griffin, TB \& Bird, WW 1987, 'Applications of mathematical programming concepts to incremental elastic-plastic analysis', Engineering Structures, vol. 9, no. 3, pp. 171-176.

Ramon, B, Roger, S \& Walla, M 1989, 'Effect of tire pressure on flexible pavement response and performanace ', in Transportation Research Record No. 1227, Transportation Research Board, Washington, DC, pp. 97-106.

Saad, B, Mitri, H \& Poorooshasb, H 2006, '3D FE Analysis of Flexible Pavement with Geosynthetic Reinforcement', Journal of Transportation Engineering, vol. 132, no. 5, pp. 402-415.

Sharp, RW 1985, 'Pavement design based on shakedown analysis', in Transportation Research Record No.1022, Transportation Research Board, Washington, DC., pp. 99107.

Werkmeister, S, Dawson, A \& Wellner, F 2001, 'Permanent Deformation Behavior of Granular Materials and the Shakedown Concept', Transportation Research Record: Journal of the Transportation Research Board, vol. 1757, pp. 75-81.

Yu, HS 2006, 'Plasticity and Geotechnics', in Advances in Mechanics and Mathematics, vol. 13, eds DY Gao \& RW Ogaden, Springer Science and Business Media, LLC., New York, USA., pp. 69-85. 